\title{
Visualization and Observation of Morphological Peculiarities of Twin Formation in Mg-Based Samples After Electrically Assisted Forming
}

\author{
Silvia Reschka ${ }^{1}$ - Gregory Gerstein ${ }^{1} \cdot$ Andrej Dalinger $^{1} \cdot$ Sebastian Herbst $^{1} \cdot$ Florian Nürnberger $^{1} \cdot$ Stephan $_{\text {Zaefferer }}{ }^{2}$
}

Received: 2 April 2019 / Revised: 16 October 2019 / Accepted: 28 October 2019 / Published online: 11 November 2019

(c) ASM International 2019

\begin{abstract}
By using electrically assisted forming the usually rather poor workability of magnesium can be improved. The processes taking place during these forming operations have a strong influence on the microstructure. However, the metallographic preparation of magnesium is challenging due to its low hardness and strong tendency to oxidize. Therefore, a reliable preparation method was developed that revealed the microstructural features caused by the electrically assisted forming. The different morphologies of twins caused by plastic deformation and of those caused by an electric impulse could clearly be distinguished.
\end{abstract}

Keywords Magnesium $\cdot$ Electroplastic effect $\cdot$ Metallographic preparation $\cdot$ Twins

\section{Introduction}

$\mathrm{Mg}$ and $\mathrm{Mg}$-based alloys offer a wide range of attractive properties, for example a low density, a high specific strength, a high specific stiffness and good damping properties [1]. Mg-alloys are therefore frequently employed for lightweight applications.

Due to their lightweight potential, Mg-alloys are widely used in the automotive and aviation industries. Parts used for such applications are often produced by forming processes. However, one of the big drawbacks of $\mathrm{Mg}$ is the poor workability caused by its hexagonal crystal structure. This is usually dealt with by heating the material to a temperature where additional slip systems are activated. Especially for large or complex products, this method increases the production costs [2,3]. While the application of electroplastic deformation technology allows the introduction of a cost effective and energy-saving manufacturing process of metal forming [4]. A new technology for improving the workability of $\mathrm{Mg}$ is based on the electroplastic effect and has already been applied in the work of Xu et al. for electroplastic rolling

Silvia Reschka

reschka@iw.uni-hannover.de

1 Institut für Werkstoffkunde, Leibniz Universität Hannover, Hanover, Germany

2 Max-Planck-Institut für Eisenforschung GmbH, Düsseldorf, Germany of AZ31. During the experiments, dynamic recrystallization and the formation of characteristic twins were observed. These twins evolved in parallel groups mainly close to the grain boundaries [3].

To clearly identify the differences in the microstructure evolution due to variation of the process parameters (e.g. current density, degree of deformation, impulse frequency) a strategy for the sample preparation has to be developed that reliably reveals not only grains and twins but even changes in twin morphology.

The fact that the metallographic preparation of $\mathrm{Mg}$ requires special attention is a well-known problem. This is caused by the fast formation of oxide layers and the low hardness of $\mathrm{Mg}$ [5].

There is a wide range of products available that are suitable for the preparation of $\mathrm{Mg}$ to allow the examination of this material despite the problems usually encountered. Some manufacturers even provide special preparation recipes for $\mathrm{Mg}$ [6-8]. These recipes have in common that for the finer preparation steps only ethanol or oil based lubricants are used. For the final polishing steps, a tendency to softer polishing cloths can be observed in the recipes. In addition, the etching strategy is also important for the description of the structure: the application of a gradual increase in etching intensity allows the morphology of the structural elements to be studied in detail. This step-by-step system for selecting the optimal etching parameters is linked to the differences in the deformation state of each specimen. Being able to 
analyze these details is crucial for further investigation of the electrically assisted forming (EAF) approach.

\section{State of the Art}

\section{Electroplastic Effect}

In the 19th century the influence of the electric field on metallic materials has already been investigated by Gerardin who showed, that the electric current can induce the motion of atoms in liquid tin solder [9]. Later on, this transport of atoms could also be observed in thin films and bulk materials $[10,11]$. The parameters usually regarded during plastic deformation are the mechanical load, temperature, environment and time. While investigating the plastic deformation, the effects of electric fields or currents are usually neglected. But often they can have an influence on the materials deformation behavior and also affect the materials recovery and recrystallization, solubility in solids, precipitation processes, grain growth, hardening and annealing [12]. As shown by Shichum and Conrad, an electric field can influence the strength in a positive way during superplastic deformation of aluminium alloys [13]. An overview of the effects of electric fields and currents on balanced properties, kinetics, microstructural properties and plasticity of ceramics and metals is given by Conrad and Jung [14]. The high value of the athermal effect of current impact on the recovery behavior of magnesium alloy was investigated in [15].

During the 60s of the twentieth century it was established that conduction electrons can cause a resistance of moving dislocations in metals [16]. Troitskii and Likhtman observed that an electric current can cause an increase of dislocation mobility [17]. Furthermore, during uniaxial deformation of zinccrystals they discovered a decrease in yield stress. Therefor they assumed that a directed electric current is able to increase dislocation mobility and can lead to the relaxation of the material [18]. Because of this, it is expected that the influence of the electric current on the mechanical properties also causes changes in the microstructure, especially in twin morphology.

A recently developed method to increase the deformability of metals and alloys is electrically assisted forming (EAF), where a current is conducted through the component during deformation. High current densities may cause the electroplastic effect, which offers a variety of advantages. One is a decrease of the flow stress. Additionally, the deformation prior to failure is increased and springback effects can be reduced. These improvements are caused by a variety of effects that occur simultaneously. Local heating is caused at lattice defects like grain boundaries, voids and impurities. This allows for a locally easier motion of dislocations. The resulting heating of the whole component depends on the materials specific resistivity and the defect density. Another effect is the direct interaction of dislocations with electrons. Electrons travelling through the material allow an easier motion of dislocations in the same direction. An additional effect occurs when the travelling electrons help to separate and re-form metallic bonds, which increases the materials ductility and makes it more workable [19].

An example for the application of the electroplastic effect during the deformation of $\mathrm{Mg}$-alloys is given in the work of Xie et al. who used an AZ31 sheet and a simple deep drawing process. The sheets were preheated before the actual deep drawing process. The electric pulses were concentrated on the flange and die corner regions. The parameters varied were the peak current density up to $250 \mathrm{~A} / \mathrm{mm}^{2}$ (calculated by us from the geometry of the samples indicated in the publication and the scheme of their deep drawing deformation) and the current pulse rate (up to $800 \mathrm{~Hz}$ ). The results show that an increase in either parameter at a constant temperature can result in an improvement of the deep drawing limit of up to $\approx 15 \%$ [1].

\section{Sample Preparation}

In the literature, a whole range of recipes can be found promising a successful metallographic preparation of $\mathrm{Mg}$. But the point is to prepare a very soft, rapidly oxidizing material. Some of the steps recommended by various companies for the preparation of such samples are compared in Table 1 [6-8]. The data presented in this table on the processing of magnesium alloys from different sources can be considered as criteria for selecting the optimal parameters to obtain a contrast with the elements of the structure of interest. It should be remembered that the preparative steps mentioned above were developed to evaluate the structure of industrially produced alloys, which usually requires a fast process for quality control reasons. When assessing changes in the microstructure of the material a significantly more thorough preparation will be needed. However, this table gives us important information for the selection of preparative operations. The literature also provides a lot of different etchants for Mg-based alloys. The etchants listed in Table 2 $[3,18,19]$ were used for deformed samples of the alloy AZ31, which among others was investigated in this work. This table shows that an important part of the selection process for optimal etching is the use of the same etchant with different concentrations of components. In addition, it is important that each technique works to achieve a specific goal: observation of precipitation in grain volume or at grain boundaries, study of twin morphology, study of grain boundaries, and so on. 


\section{Materials and Methods}

AZ31 and technically pure $\mathrm{Mg}$ were investigated. AZ31 is a $\mathrm{Mg}-\mathrm{Al}-\mathrm{Zn}$-alloy with a medium strength and is widely used as a forgeable and weldable alloy, providing a comparatively good corrosion resistance [20].

To investigate the influence of the electroplastic effect on the microstructure evolution, samples of both materials were treated in a special testing machine that allows to employ high current impulses parallel to the mechanical load direction. The equipment was described by Demler et al. [21]. In order to avoid a strong voltage drop during the impulse, double layer capacitors are used as the energy source. A compressive load of $20 \mathrm{MPa}(\mathrm{Mg}$ and AZ31) and $50 \mathrm{MPa}$ (AZ31) was applied to the rectangular cuboid samples ( $3 \mathrm{~mm} \times 3 \mathrm{~mm} \times 6 \mathrm{~mm}$ ) as depicted in Fig. 1b during the application of the electric impulse. The stresses were in the elastic region of the AZ31 alloy.

Based on an assessment of the impact of the quality and properties of each of the polishing materials given in Table 1, the tested samples were metallographically prepared using a combination of the methods mentioned in Table 1 and described in Table 3. They were ground in two steps, namely with P1200 and P2500 SiC-paper using water as a lubricant and ethanol for the last step. Subsequently, two polishing steps using 6 and $3 \mu \mathrm{m}$ diamond

Table 1 Metallographic preparation methods for Mg-samples

\begin{tabular}{|c|c|c|c|}
\hline Preparation step & Struers [5] & Buehler [6] & ATM [7] \\
\hline Grinding & SiC-paper, water & Wax coated paper, water & SiC-paper,coated with paraffin wax \\
\hline Polishing $9 \mu \mathrm{m}$ & $\begin{array}{l}\text { MD-Largo, Green/Blue (water/alcohol } \\
\text { based) }\end{array}$ & $\begin{array}{l}\text { TexMet } \\
9 \mu \mathrm{m} \text { MetaDi oil based diamond suspension }\end{array}$ & BETA, alcohol or oil based \\
\hline Polishing $6 \mu \mathrm{m}$ & MD-Dur, Green/Blue (water/alcohol based) & & \\
\hline Polishing $3 \mu \mathrm{m}$ & MD-Mol, Red, Emulsion & $\begin{array}{l}\text { TexMet } \\
3 \mu \mathrm{m} \text { MetaDi oil based diamond suspension }\end{array}$ & SIGMA, alcohol or oil based \\
\hline Polishing $1 \mu \mathrm{m}$ & & $\begin{array}{l}\text { TexMet } \\
1 \mu \mathrm{m} \text { MetaDi oil based diamond suspension }\end{array}$ & ZETA, alcohol or oil based \\
\hline Final polishing & MD-Nap or MD-Chem. OP-S or OP-U & $\begin{array}{l}\text { ChemoMet, } 0.05 \mu \mathrm{m} \text { MasterPolish or } \\
\text { MasterPrep }\end{array}$ & OMEGA, Etosil E, $0.06 \mu \mathrm{m}$ \\
\hline
\end{tabular}

Table 2 Etchants for Mg-based alloys

\begin{tabular}{|c|c|c|c|}
\hline References & [3] & [9] & [10] \\
\hline Material & AZ31 & AZ31 & AZ31 \\
\hline Etchant recipe & $\begin{array}{l}5 \mathrm{ml} \text { acetic acid }+6 \mathrm{~g} \text { picric acid }+10 \mathrm{ml} \\
\mathrm{H}_{2} \mathrm{O}+100 \mathrm{ml} \text { ethanol }(95 \%)\end{array}$ & $\begin{array}{l}6 \% \text { picric acid in } 70 \mathrm{ml} \text { ethanol }+10 \mathrm{ml} \\
\text { acetic acid }+10 \mathrm{ml} \text { purified water }\end{array}$ & $\begin{array}{l}3 \mathrm{~g} \text { malic acid }+2 \mathrm{ml} \text { nitric } \\
\text { acid }+95 \mathrm{ml} \text { distilled } \\
\text { water }\end{array}$ \\
\hline
\end{tabular}

(a)

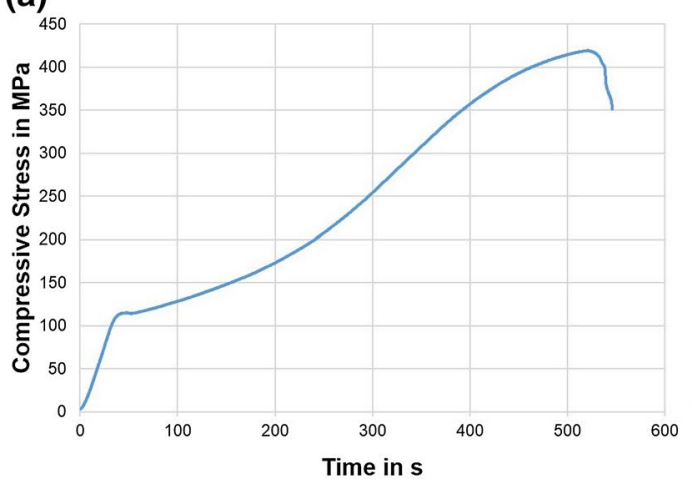

(b)

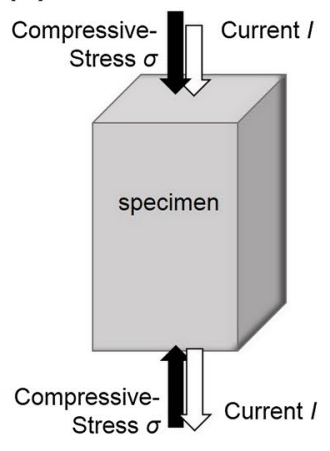

(c)

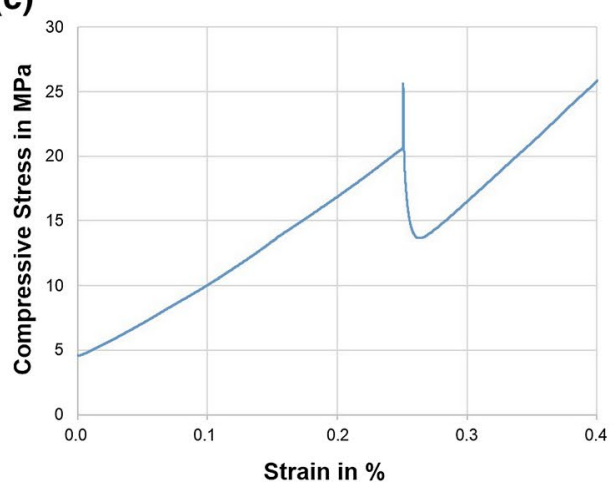

Fig. 1 (a) Compressive stress vs. time for AZ31 to identify the elastic region, (b) schematic depiction of simultaneous mechanical load and current flow, (c) compression test on AZ31 with superimposed elec- tric impulse of $2 \mathrm{kA}$ for $1 \mathrm{~ms}$ applied at a compressive stress of about $20 \mathrm{MPa}$, i.e. within the elastic regime 
Table 3 Metallographic preparation steps

\begin{tabular}{ll}
\hline Pure Mg & AZ31 \\
\hline Grinding P1200 & Grinding P1200 \\
Grinding P2500 & Grinding P2500 \\
Polishing $6 \mu \mathrm{m}$, MD Mol, lubricant yellow & Polishing $6 \mu \mathrm{m}$, MD Mol, lubricant yellow \\
Polishing $3 \mu \mathrm{m}$, MD Mol, lubricant yellow & Polishing $3 \mu \mathrm{m}$, MD Mol, lubricant yellow \\
Chemical polishing & Chemical polishing \\
Polishing $1 \mu \mathrm{m}$, MD Nap, lubricant yellow & Polishing $1 \mu \mathrm{m}$, MD Nap, lubricant yellow \\
Chemical polishing & $\ldots$
\end{tabular}

Fig. 2 Preparation artefacts at the edges of an AZ31 sample

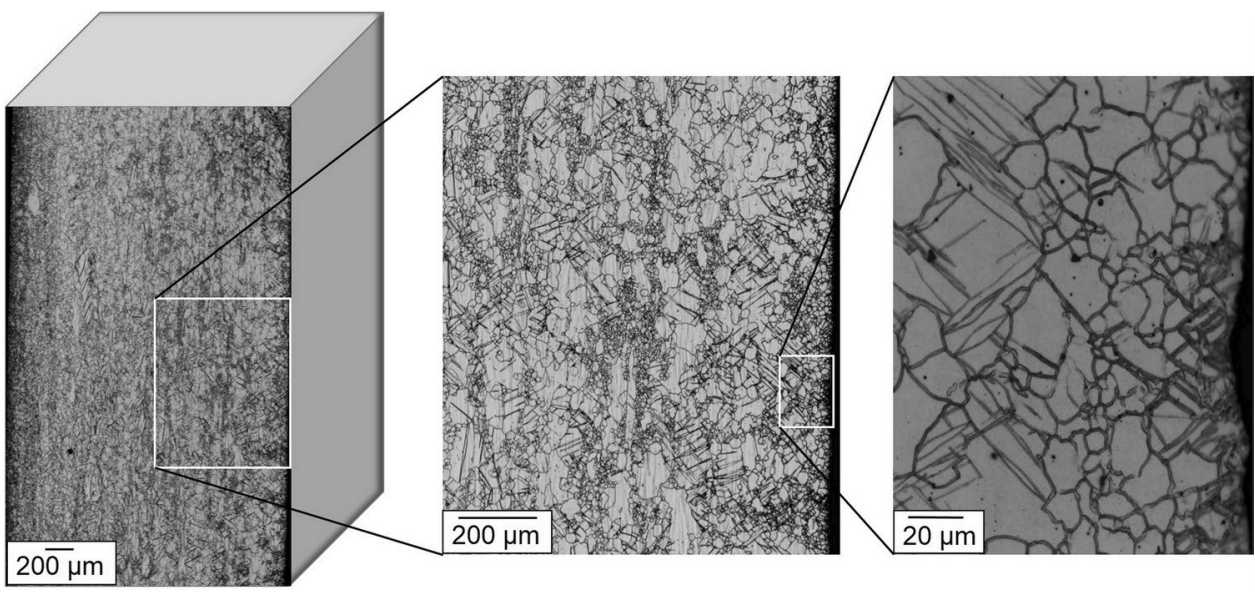

suspension and two MD Mol polishing cloths (very soft cloth for final polishing, meets the requirements also for pure magnesium-Struers) were carried out. Afterwards, for the removal of traces of deformation brought in by polishing, the samples were chemically polished $(2 \mathrm{ml}$ nitric acid $+3 \mathrm{ml}$ hydrochloric acid, $95 \mathrm{ml}$ ethanol) to remove the traces of the previous treatments. In the next step a $1 \mu \mathrm{m}$ diamond suspension and a MD Nap polishing cloth (Struers) were used for manual polishing. For these three polishing steps, the ethanol based Lubricant Yellow (Struers) was used. Finally, the pure $\mathrm{Mg}$ samples were again chemically polished as described.

A range of different etchants and combinations were used to observe the relevant microstructural details in the samples. For AZ31 a 1\% nitric acid was used to reveal the different phases. Another promising etchant as listed in Table 2 was picric acid. The samples were etched using a $20 \%$ acetic/picric acid $(20 \mathrm{ml}$ acetic acid +3 g picric acid $+20 \mathrm{ml}$ water $+50 \mathrm{ml}$ ethanol). This revealed grain boundaries and twins in the AZ31 alloy as well as in pure $\mathrm{Mg}$. During etching, sometimes a film can form on the sample surface that impedes the proper examination of the sample. In that case, a second etchant with the same components but different composition $(5 \mathrm{ml}$ acetic acid $+6 \mathrm{~g}$ picric acid $+10 \mathrm{ml}$ water $+100 \mathrm{ml}$ ethanol, Table 2) was used to remove this film.

\section{Results}

As depicted in Fig. 2, it is crucial to choose the right area of the sample surface for observation since the edges of the specimens can show artefacts of sample cutting and preparation.

The chemical polishing of the samples revealed the grain boundaries for the pure $\mathrm{Mg}$, but no twin boundaries. The AZ31-specimens showed no grain boundaries after polishing. To make sure these and the twins would also be visible, an etching step was needed for both materials. Hence, a 0.5 or $1 \%$ nitric acid was carefully used to reveal the different structural elements. For both materials used in this study, only the precipitates were highlighted by this treatment. The grain boundaries and twins only became visible after etching with acetic/picric acid. As grain boundaries and twins provide insight into the mechanisms taking place during deformation this can be considered the most suitable etchant for the purpose of this study. In Fig. 3 micrographs of AZ31 after polishing, etching with $1 \%$ nitric acid and $20 \%$ acetic/picric acid are compared. Figure 4 compares micrographs taken of pure $\mathrm{Mg}$ in the polished state, after chemical polishing, and after etching with $20 \%$ acetic/picric acid. Figure 5a shows a sample of pure $\mathrm{Mg}$ that was treated with 10 impulses under a compressive load of $20 \mathrm{MPa}$. In order to compare 
(a)

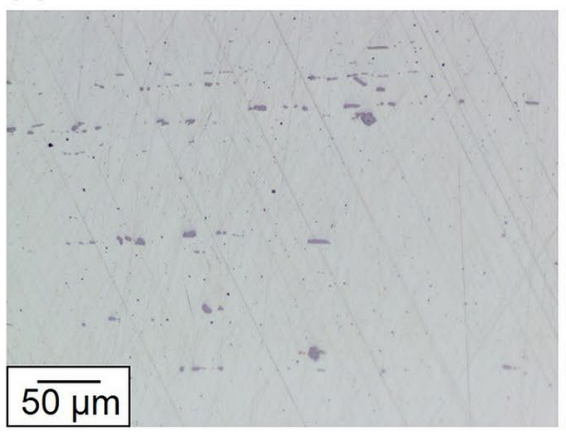

(b)

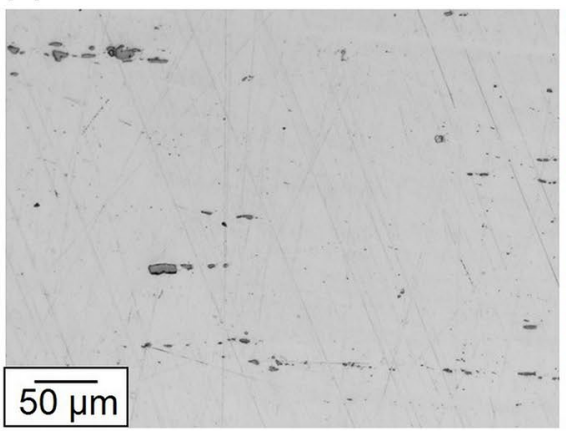

(c)

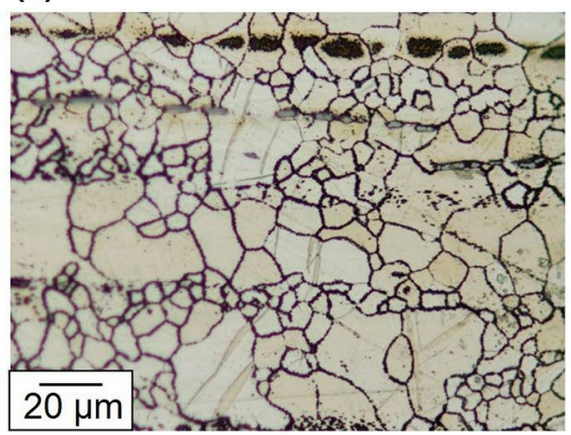

Fig. 3 AZ31 (a) polished with $1 \mu \mathrm{m}$ diamond suspension, (b) etched using 1\% nitric acid, (c) etched using 20\% acetic/picric acid

(a)

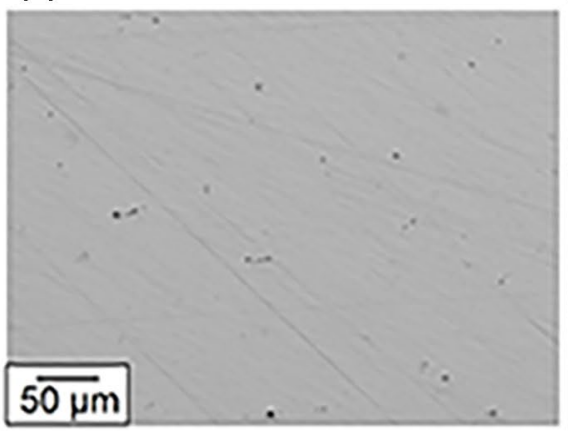

(b)

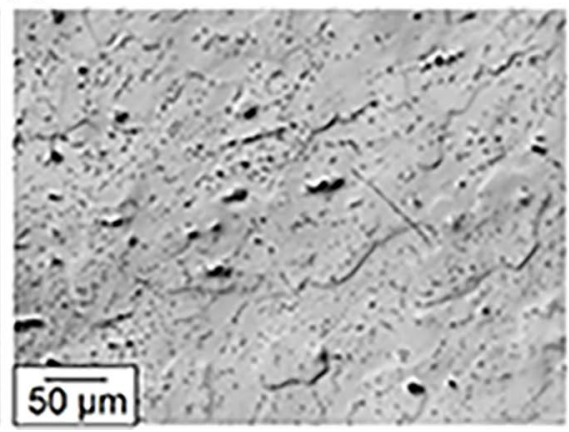

(c)

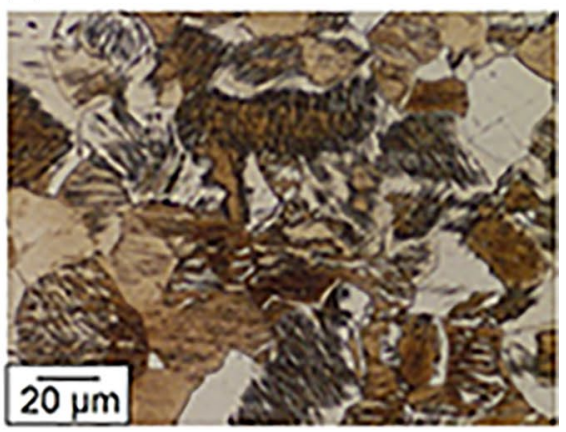

Fig. 4 Pure magnesium (a) polished with $1 \mu$ m diamond suspension, (b) chemically polished, (c) etched using 20\% acetic/picric acid

(a)

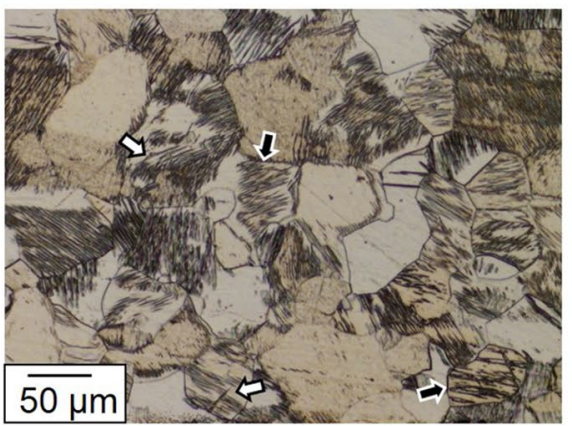

(b)

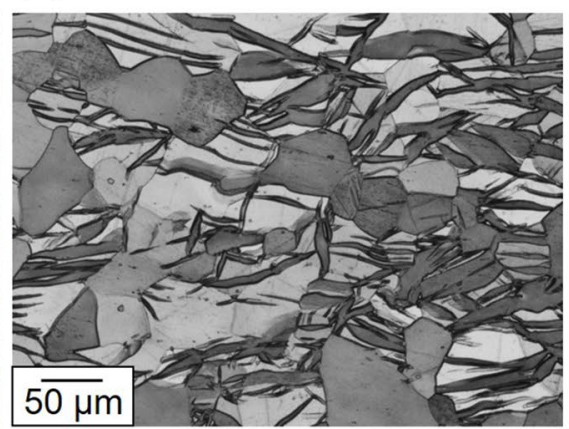

(c)

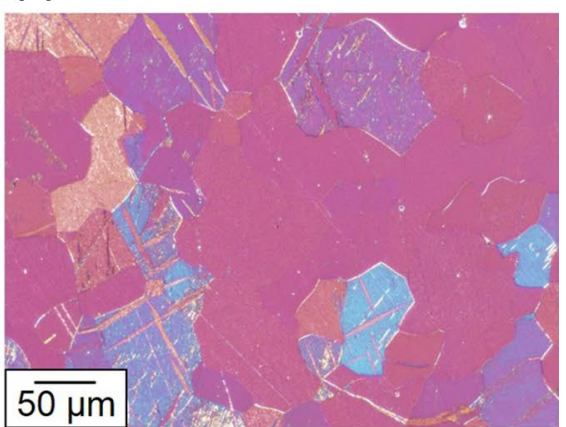

Fig. 5 Pure Mg etched using 20\% acetic/picric acid, (a) $20 \mathrm{MPa}, 10$ impulses, black arrows: parallel groups of twins, white arrows: intersecting twins, (b) $20 \mathrm{MPa}$, single intersecting twins, (c) $60 \mathrm{MPa}$, increasing volume fraction of coarse twins

the morphology of the twin structures formed at different levels of deformation, samples of the same geometry were tested under similar loads but without impulses (Fig. 5b). Further samples were tested at loads comparable to the yield strength of pure magnesium (Fig. 5c). Figure 6 shows a typical example of the microstructure in a sample loaded at $30 \mathrm{MPa}$, in which the electrical impulse lead to the generation of thin twin bands. The orientation of grains, twins and twin bands can be checked using EBSD. A basic scheme of EBSD analysis of twins in grains is presented in Fig. 7a-f. 


\section{Discussion}

The work of Li et al. describes twin formation and slip of dislocations as two competing mechanisms during EAF. Which mechanism predominates is highly dependent on the parameters applied. One of these parameters was a varying frequency of the electric impulses. This frequency had a strong influence on the microstructure evolution

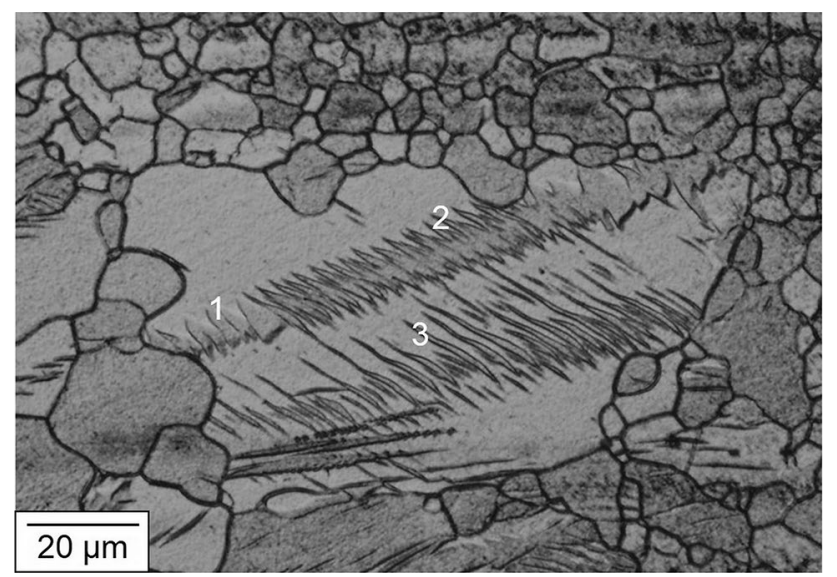

Fig. 6 AZ31 sample, 1 Impulse, $2300 \mathrm{~A} / \mathrm{mm}^{2}, 30 \mathrm{~V}, 1 \mathrm{~ms}$, metallographically prepared according to Table 3 , etched with picric acid; crystallographically equivalent twins $\{10 \overline{1} 1\}$ (zone axis $\langle 1 \overline{2} 10\rangle$ )
[22]. During the electroplastic rolling described by $\mathrm{Xu}$ et al., dynamic recrystallization took place and resulted in the formation of smaller grains. The electroplastic rolling also induced the formation of new twins [3]. These twins arrange in parallel aligned groups, which can intersect.

The microstructure of the samples treated with 10 electric impulses during deformation is compared to that of samples deformed at a similar load, but without impulses (Fig. 5a and b) and to that deformed at higher loads, also without electric impulses. The latter ones show the formation of large single twins, but only in grains oriented advantageously to the loading direction with a comparatively high Schmid Factor. In this case, the size and volume fraction of the twins increase with the degree of deformation.

The microstructural features mentioned above can be easily recognized by using the described preparation technique. Figure 6 depicts a micrograph of a sample that received one high current impulse. The images after etching depicted in Figs. 5 and 6 clearly revealed different groups of twins. Twin groups 1-3 (Fig. 6) are located in the same plane, but have different orientations. This way they form twin bands [23]. The analysis of the EBSD results obtained by loading the sample with the impact of electrical impulse has shown (Fig. 7) that the efficiency of the influence of an electrical current on the deformation of the grain and on the morphology of twins in the grain obviously depends very much on the orientation of the grain in relation to the loading direction, characterized by the Schmid Factor (SF). Unlike the (a)

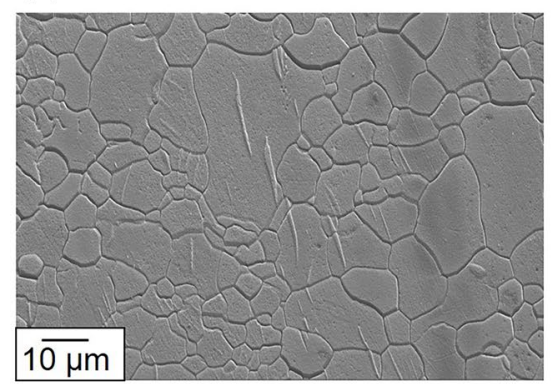

(d)

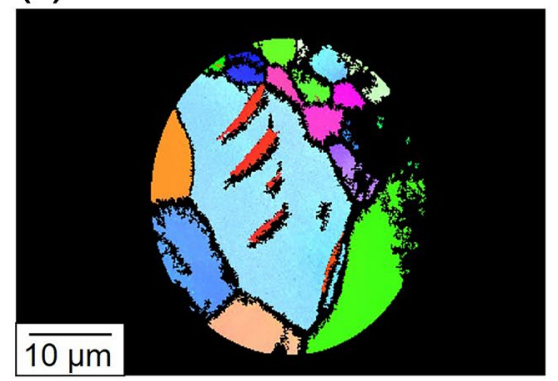

(b)

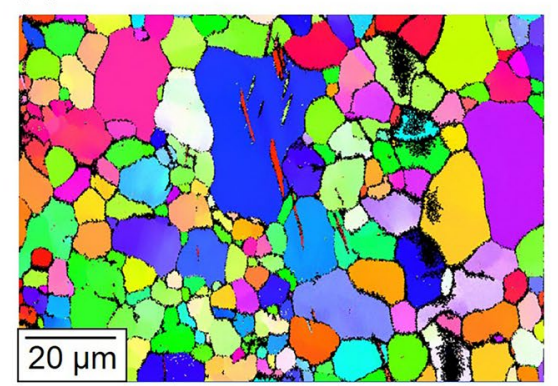

(e)

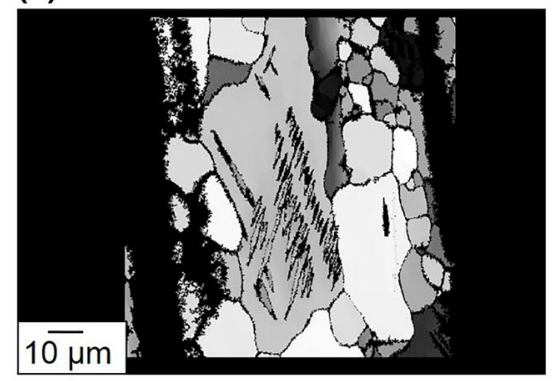

(c)

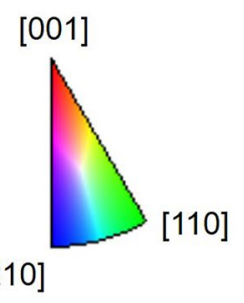

(f)

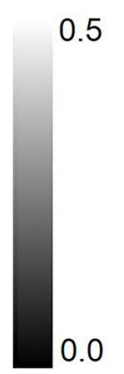

Fig. 7 Procedure for characterizing the grain and twin orientation using EBSD: (a) SEM imaging of the microstructure in a macro area of the sample, (b) EBSD image of the observed macro area, (c) inverse pole figure color key for the EBSD images, (d) EBSD map of the micro area, (e) Schmid Factor, (f) legend for Schmid Factor 
twin bands investigated in the work of Molodov et al. (Figure $8 \mathrm{~b}$ ), in the present case the electrically induced twins in grains with a high $\mathrm{Schmidt}$ Factor (in this case $\mathrm{SF}=0.3-0.4$ ) are all aligned and oriented the same way (Fig. 8c), while the surrounding grains towards the edge of the figure (e.g. two grains $(\mathrm{SF}=0.2-0.3)$ to the left of the number 1 in the Fig. 6) show a twin morphology exactly like that seen in the work of Molodov et al. and graphically shown in Fig. 9(b).

Ultimately, the morphology of the resulting twins will always be determined by the nature of the distribution of local stresses in the grains and the corresponding nature of the dislocation slip. Therefore, the similar morphologies of twins can be provided both as a result of mechanical influence and as a result of electric current influence. However, the essential criterion for the difference between twins arising from mechanical loading and the additional application of electric current is the place of twin growth and location (nature of distribution) of twins in the grain volume. With purely mechanical loading, the twins grow at the grain boundaries, forming coarse, large twins (Fig. 5b and c) and a small part of the small twins (depending on the nature and type of load). When electric current is applied, bands of fine and small twins are formed inside the grain volume (Fig. 6).

The method used in the present study also enables the observation of secondary twins as can be seen in Fig. 9. The micrographs depicted show possible further development of twins in a sample deformed to $\varepsilon=0.18$ and treated with one high current pulse. Figure $7 \mathrm{c}$ schematically shows the formation of secondary twins in the primary twins as seen in the micrograph of Fig. $9 \mathrm{~b}$.

By summarizing the analysis of the morphology of twins formed due to mechanical load or caused by EAF shows differences. The twins generated by inducing additional electric pulses while a sample is loaded in its plastic region are different to those formed by plain mechanical load. One of the main differences is that only the latter kind is connected to the grain boundaries, as is depicted in Fig. 8. Apparently, the local stresses created by the application of electric impulse in the grain volume are rather low and lead to the appearance of twin bands only in grains oriented advantageously to the axis of loading (i.e. with a high Schmid Factor). (a)

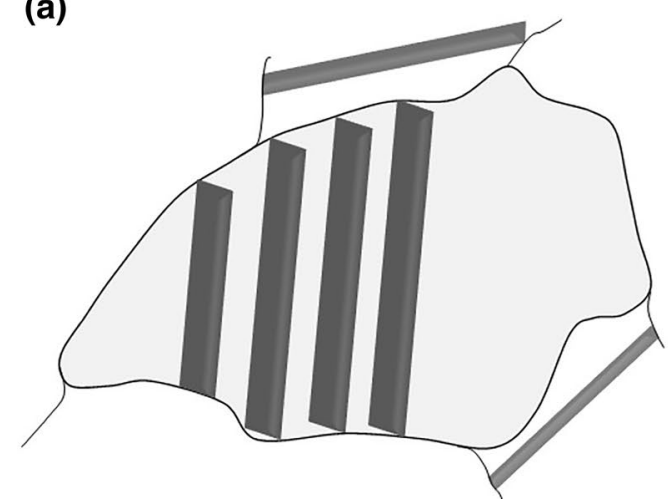

(b)

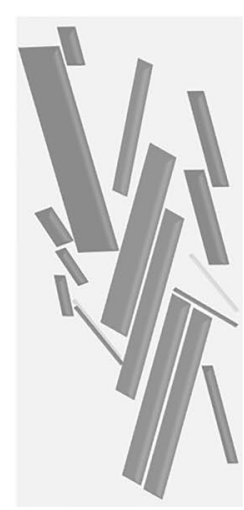

(c)

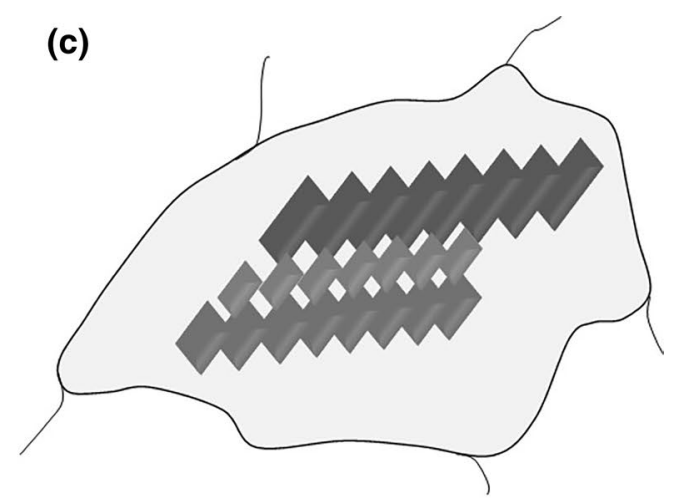

Fig. 8 Typical twin morphologies (a) after conventional plastic deformation $0.01<\varepsilon<0.3$, (b) twin band after conventional plastic deformation (as in the work of Molodov et al. [23]), (c) rows of twins' bands formed during EAF

(a)

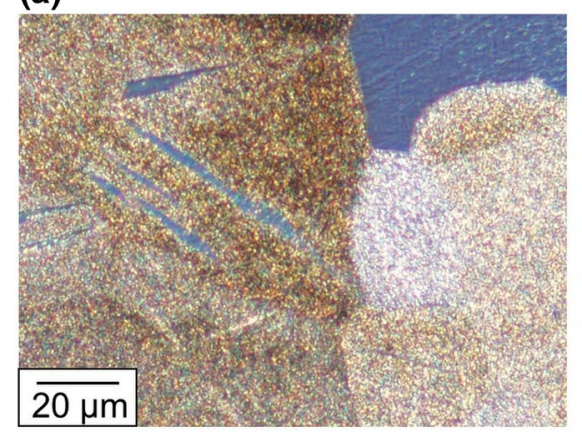

(b)

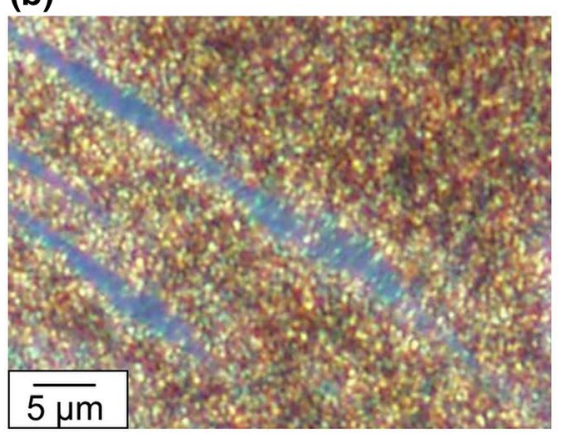

(c)

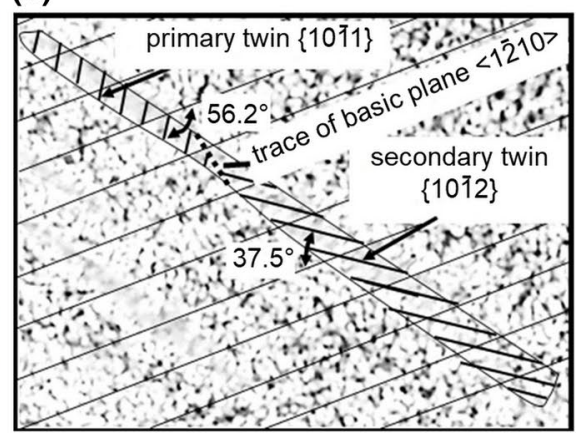

Fig. 9 Twin formation $\{10 \overline{1} 2\}$ (zone axis $\langle 1 \overline{2} 10\rangle$ after EAF: (a) primary twins inside a grain (meso scale), (b) evolution of twins (micro scale), (c) schematic depiction of b) 
The described preparation technique is able to reliably show the formed twins in detail for further analysis of the mechanisms during EAF.

According to the work of Yamakov et al. [24], twin growth is usually initiated by partial Shockley-dislocations or by migration of splitted grain boundaries. Based on their simulations, Zhu et al. [25] showed another mechanism for twin growth, namely the overlapping of two dislocations in adjacent slip planes. Thus, the twins produced solely by mechanic load are mostly directly connected to grain boundaries (Fig. 9a) and the orientation of the twins within a twin band is not consistent (Fig. 8b). In contrast, twins induced by EAF are grouped within the grain and exhibit the same orientation, which is typical for the third mechanism described by Zhu et al. (Fig. 9c).

The possibility of developing different twin/matrix interfaces was considered by $\mathrm{Li}$ and Ma by using molecular dynamics simulations and transmission electron microscopy. They found that the application of mechanical load combined with a high current pulse can lead to the nucleation of new twinning dislocations. Gliding of these dislocations along the twin/matrix interface leads to twin growth in the lateral and normal directions of the initial twin plane [26].

\section{Conclusion}

The microstructural evolution caused by the electroplastic effect could be observed in optical microscopy after determining a reliable method for the challenging metallographic preparation of Mg-based samples to reveal twin boundaries. As the microstructural changes caused by the EPE are fairly small, several standardized methods were evaluated to find the most suitable method. This included a specific sequence of acetic/picric acid etching using different concentrations of solutions. The applied method of sample surface preparation allowed to detect the development of thin twin bands in the microstructure under the influence of electric current impulses. The microstructural features observed match well with similar results found in the literature. The comparison of the change in the morphology of the twin structure of the material under the influence of different levels of mechanical load and simultaneous influence of mechanical load and electrical impulses is also carried out.

Acknowledgments Funded by the Deutsche Forschungsgemeinschaft (DFG, German Research Foundation) - 319282412

\section{References}

1. H. Xie, X. Dong, Z. Ai, Q. Wang, F. Peng, K. Liu, F. Chen, J. Wang, Experimental investigation on electrically assisted cylindrical deep drawing of AZ31B magnesium alloy sheet. Int. J.
Adv. Manuf. Technol. 2016(86), 1063-1069 (2016). https://doi. org/10.1007/s00170-015-8246-0

2. L. Guan, G. Tang, P.K. Chu, Recent advances and challenges in electroplastic manufacturing processing of metals. J. Mater. Res. 25(7), 1215-1224 (2010). https://doi.org/10.1557/jmr.2010.0170

3. Z. Xu, S. Tian, F. Ding, H. Tian, Research of electroplastic rolling of AZ31Mg alloy strip. J. Mater. Process. Technol. 2007, 128-133 (2007). https://doi.org/10.1016/j.jmatprotec.2006.07.019

4. H. Nguyen-Tran, H. Oh, S. Hong, H.N. Han, J. Cao, S. Ahn, D.A. Chun, Review of electrically-assisted manufacturing. Int. J. Precis. Eng. Manuf. Green Technol. 2(4), 365-376 (2015). https://doi. org/10.1007/s40684-015-0045-4

5. G.F. Vander Voort, Metallography Principles and Methods (ASM International, Cleveland, 1999). (ISBN-13: 978-0-87170-672-0, ISBN-10:0-87170-672-5)

6. L. Bjerregaard, K. Geels, B. Ottesen, M. Rückert, Metalog Guide (Struers, Cleveland, 2002). (ISBN 87-987767-0-3)

7. G.F. Vander Voort, BUEHLER Sum ${ }^{\circledR}$ Met $^{\mathrm{TM}}$ (Buehler, Lake Bluff, 2011). (ISBN 0-9752898-0-2)

8. ATM Advanced Materialography, Probenpräparation, Standardmethoden für die materialographische Analyse. https:// www.atm-m.de/de/downloads/praeparationsmethoden/ (2016). Accessed 6 March 2019

9. M. Gerardin, Comptes rendus hebdomadaires des séances de l'Académie des sciences 55(1861), 727-730 (1861)

10. F.M. D'Heurle, P.S. Ho, in Thin Films-Interdiffusion and Reactions, ed. by J.M. Poate, K.N. Tu, J.W. Mayer (Wiley-Interscience, New York, 1978). (ISBN 0-4710223-8-1)

11. R.E. Hummel, in Metals and Alloys, ed. by R.E. Hummel, H.B. Huntington (AIME, New York, 1977). (ISBN 0-3173486-7-1)

12. H. Conrad, Mater. Trans. 46(2005), 1083-1087 (2005). https:// doi.org/10.2320/matertrans.46.1083

13. L. Shichum, H. Conrad, Scr. Mater. 39(7), 847-851 (1998). https ://doi.org/10.1016/s1359-6462(98)00268-1

14. H. Conrad, K. Jung, Mater. Manuf. Processes 19(4), 573-585 (2004). https://doi.org/10.1081/amp-200028063

15. S.-J. Kim, S.-D. Kim, D. Yoo, J. Lee, Y. Rhyim, D. Kim, Metall. Mater. Trans. A 1, 6368-6373 (2016). https://doi.org/10.1007/ s11661-016-3804-0

16. V.I. Alshits, V.L. Indeborn, in Dislocations in Solids. Band 7, ed. by F.R.N. Nabarro (North-Holland, Amsterdam, 1986), pp. 43-111. (USBN 978-0-444-51888-0)

17. O.A. Troitskii, V.I. Likhtman, Dokl. Akad. Nauk SSSR 148, $332 \mathrm{ff}$ (1963)

18. O.A. Troitskii, V.I. Spitsyn, Sov. Phys. Dokl. 21, 1307-1310 (1976)

19. W.A. Salandro, J.J. Jones, C. Bunget, L. Mears, T. Roth, Electrically Assisted Forming: Modeling and Control (Springer International Publishing, Cham, 2015). (ISBN 978-3-319-08879-2)

20. H.E. Friedrich, B.L. Mordlike, Magnesium Technology, Metallurgy, Design Data (Applications. Springer, Berlin, 2006). (ISBN10 3-540-20599-3; ISBN-13 978-3-540-20599-9)

21. E. Demler, G. Gerstein, A. Dalinger, A. Epishin, D. Rodman, F. Nürnberger, Influence of high-current-densitiy impulses on the compression behavior: experiments with iron and a nickel-based alloy. J. Mater. Eng. Perform. (2016). https://doi.org/10.1007/ s11665-016-2457-x

22. X. Li, G. Tang, J. Kuang, X. Li, J. Zhu, Effect of current frequency on the mechanical properties, microstructure and texture evolution in AZ31 magnesium alloy strips during electroplastic rolling. Mater. Sci. Eng. A 2014, 404-413 (2014). https://doi. org/10.1016/j.msea.2014.06.075

23. K.D. Molodov, T. Al-Samman, D.A. Molodov, G. Gottstein, On the role of anomalous twinning in the plasticity of magnesium. Acta Mater. 103, 711-723 (2016). https://doi.org/10.1016/j.actam at.2015.10.043 
24. V. Yamakov, D. Wolf, S.R. Phillpot, A.K. Mukherjee, H. Gleiter, Dislocation processes in the deformation of nanocrystalline aluminium by moldecular-dynamics simulation. Nat. Mater. 1, 1 (2002). https://doi.org/10.1038/nmat700

25. Y.T. Zhu, X.Z. Liao, X.L. Wu, Deformation twinning in nanocrystalline materials. Prog. Mater Sci. 57, 1-62 (2012). https://doi. org/10.1016/j.pmatsci.2011.05.001

26. B. Li, E. Ma, Zonal dislocations mediating $\{10 \overline{1} 1\} 10 \overline{1} \overline{2}$ twinning in magnesium. Acta Mater. 57, 1734-1743 (2009). https://doi. org/10.1016/j.actamat.2008.12.016
Publisher's Note Springer Nature remains neutral with regard to jurisdictional claims in published maps and institutional affiliations. 